Case Report

\title{
A Case of Laparoscopic Resection for Carcinoma of the Gastric Remnant following Proximal Gastrectomy Reconstructed with Jejunal Interposition
}

\author{
Kazuhito Yajima, Yoshiaki Iwasaki, Ken Yuu, Ryouki Oohinata, Misato Amaki, \\ Yoshinori Kohira, Souichiro Natsume, Satoshi Ishiyama, and Keiichi Takahashi
}

Department of Surgery, Tokyo Metropolitan Cancer and Infectious Diseases Center, Komagome Hospital, 3-18-22 Honkomagome, Bunkyo-ku, Tokyo 113-8677, Japan

Correspondence should be addressed to Kazuhito Yajima; yajikazu@nifty.com

Received 5 October 2015; Revised 14 February 2016; Accepted 14 February 2016

Academic Editor: Boris Kirshtein

Copyright (C) 2016 Kazuhito Yajima et al. This is an open access article distributed under the Creative Commons Attribution License, which permits unrestricted use, distribution, and reproduction in any medium, provided the original work is properly cited.

\begin{abstract}
A 72-year-old Japanese man had a history of proximal gastrectomy for early gastric cancer located in the upper third of the stomach in 2007. Our usual treatment strategy for early gastric cancer in the upper third of the stomach in 2007 was open proximal gastrectomy reconstructing by jejunal interposition with a $10 \mathrm{~cm}$ single loop. Upper gastrointestinal fiberscopy for annual followup revealed a type 0-IIc-shaped tumor with ulcer scar, $4.0 \mathrm{~cm}$ in size, located in the gastric remnant near the jejunogastrostomy. A clinical diagnosis of cancer of the gastric remnant, clinical T1b(SM)N0M0, Stage IA, following the proximal gastrectomy was made and a laparoscopic approach was selected because of the cancer's early stage. Remnant total gastrectomy with D1 plus lymphadenectomy was carried out with five ports by a pneumoperitoneal method. Complete resection of the reconstructed jejunum was undergone along with the jejunal mesentery. Reconstruction by the Roux-en-Y method via the antecolic route was selected. Total operative time was $395 \mathrm{~min}$ and blood loss was $40 \mathrm{~mL}$. Our patient was the first successful case of resection for carcinoma of the gastric remnant following proximal gastrectomy reconstructed with jejunal interposition in a laparoscopic approach.
\end{abstract}

\section{Introduction}

Laparoscopic gastrectomy has become widely used for the treatment of early gastric cancer in Japan; the feasibility of laparoscopic distal gastrectomy in particular has been assessed in several studies [1-3]. However, laparoscopic procedures are more challenging in patients with previous abdominal surgery because of a higher risk of enteric injury, technical difficulties associated with adhesions, and longer operative times. In terms of the recent advantages of the laparoscopic technique, several reports have presented the usefulness of the laparoscopic approach for patients with remnant gastric cancer following radical distal gastrectomy [4-12]. We here present a case of laparoscopic resection for carcinoma of the gastric remnant following proximal gastrectomy reconstructed with jejunal interposition.

\section{Case Presentation}

A 72-year-old Japanese man had a history of proximal gastrectomy for early gastric cancer located in the upper third of the stomach in 2007. Our usual treatment strategy for early gastric cancer in the upper third of the stomach at this time was open proximal gastrectomy reconstructing by jejunal interposition with a $10 \mathrm{~cm}$ single loop. In this patient, interposed jejunum was approached via the retrocolic route. Lymphadenectomy was D1 (station numbers 1, 2, 3a, 4sa, 4sb, and 7) according to the Japanese Gastric Cancer Association (JGCA) guidelines for initial proximal gastrectomy [13]. Upon physical examination, he was found to be $165 \mathrm{~cm}$ in height and weighed $55 \mathrm{~kg}$. There was an upper middle operative scar, $17 \mathrm{~cm}$ in length, in his abdomen. All of the laboratory data were within the normal range and the tumor markers 


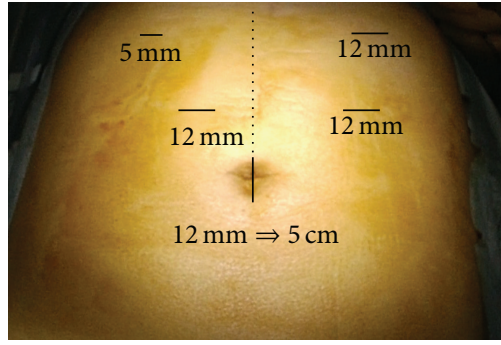

(a)

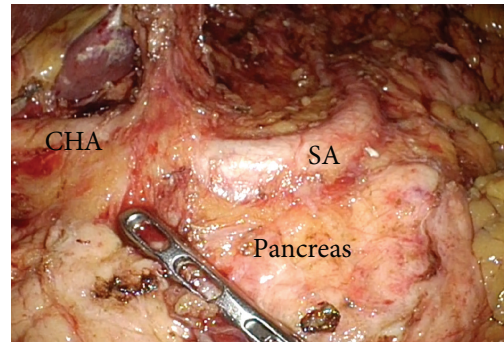

(c)

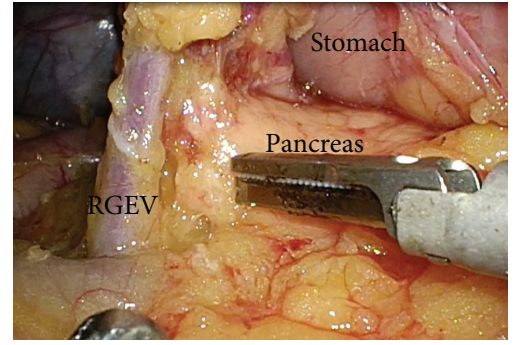

(b)

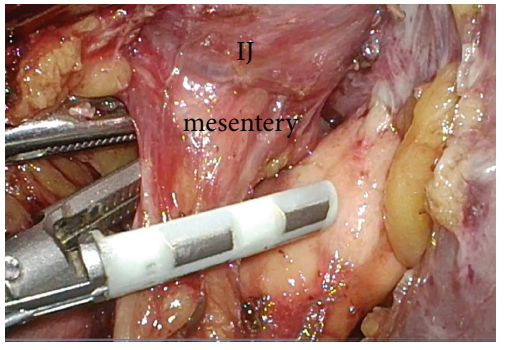

(d)

FIGURE 1: Port sites and lymphadenectomy at laparoscopic remnant total gastrectomy. (a) The port sites and scar of initial gastrectomy (dotes line). (b) Station number 6 lymph nodes were completely removed (RGEV; right gastroepiploic vein). (c) The suprapancreatic lymph nodes (station numbers 8a, 9, and 11p) were dissected en bloc (CHA; common hepatic artery, SA; splenic artery). (d) The mesentery of the interposed jejunum (IJ) was transected using a vessel sealing system (LigaSure ${ }^{\mathrm{TM}}$ Blunt Tip $5 \mathrm{~mm}-37 \mathrm{~mm}$, Covidien, Tokyo, Japan).

CEA and CA $19-9$ were $7.4 \mathrm{ng} / \mathrm{mL}$ and $9.7 \mathrm{U} / \mathrm{mL}$, respectively. Upper gastrointestinal fiberscopy for annual follow-up revealed a type 0 -IIc-shaped tumor with ulcer scar, $4.0 \mathrm{~cm}$ in size, located in the gastric remnant near the jejunogastrostomy (Figure 1). Biopsy specimen showed well-differentiated adenocarcinoma. A clinical diagnosis of early gastric cancer according to the Japanese Classification of Gastric Carcinoma [14], T1b(SM)N0M0, Stage IA, following the proximal gastrectomy was made. A laparoscopic approach was selected for remnant gastrectomy because of the cancer's early stage.

Surgery was carried out with five ports by the pneumoperitoneal method using our usual laparoscopic technique (Figure 1(a)). The lateral segment of the liver was retracted using a Nathanson Liver Retractor (Cook Surgical, Bloomington, Indianapolis, USA). At initial laparoscopy, there was a little adhesion in the median abdominal incision. At first, adhesion was removed as much as possible and omentum was dissected to open the bursa. The tightest adhesion in this operation was that between the lateral segment of the liver and the dissected lesser curvature of the remnant stomach. The right gastroepiploic artery and vein were clipped and divided, and station number 6 lymph nodes were completely removed (Figure 1(b)). After dividing the right gastric artery (station number 5), the duodenum was transected using a linear stapler $\left(\mathrm{GIA}^{\mathrm{TM}}\right.$ Tri-Staple ${ }^{\mathrm{TM}} 60 \mathrm{~mm}$, purple $60 \mathrm{~mm}$, Covidien, Tokyo, Japan). The suprapancreatic lymph nodes (station numbers 8a, 9, and 11p) could be easily dissected en bloc because these regions were not dissected at initial proximal gastrectomy (Figure 1(c)). After gastrectomy, the reconstructed jejunum was resected. The mesentery of the interposed jejunum was transected using a vessel sealing system (LigaSure ${ }^{\mathrm{TM}}$ Blunt Tip $5 \mathrm{~mm}-37 \mathrm{~mm}$, Covidien)
(Figure 1(d)). After the abdominal esophagus had been scarified circumferentially, the esophagus was transected using a linear stapler on the proximal side of the anastomosis of the esophagojejunostomy at initial proximal gastrectomy (Figure 2(a)). The remnant stomach and interposed jejunum were successfully reduced back into the peritoneal cavity through the umbilical port-side. A minilaparotomy incision of about $5 \mathrm{~cm}$ was made in the umbilical port site, for an Alexis ${ }^{\circledR}$ Wound Retractor S (Applied Medical Resources Co., Tokyo, Japan). Reconstruction using the Roux-en-Y method via the antecolic route was performed. At first, jejunojejunostomy was carried out by side-to-side anastomosis using a linear stapler extracorporeally (Figure 2(b)). Next, esophagojejunostomy was performed by an end-to-side anastomosis using a circular stapler (DST Series ${ }^{\mathrm{TM}}$ EEA $^{\mathrm{TM}}$ Staplers, $25 \mathrm{~mm}$, Covidien) (Figures 2(c) and 2(d)). Total operative time was $395 \mathrm{~min}$ and blood loss was $40 \mathrm{~mL}$.

The postoperative course was uneventful and the patient was discharged on the 10th postoperative day. The resected stomach contained a superficial depressed-type tumor, $37 \times$ $17 \mathrm{~mm}$ in size (Figure 3, black arrowhead). Histological examination revealed well-differentiated adenocarcinoma to the depth of the mucosa, with no lymph node metastasis, which was pathologically classified as Stage IA.

\section{Discussion}

We have described a 72-year-old Japanese man who underwent a laparoscopic approach for carcinoma of the gastric remnant following proximal gastrectomy reconstructed with jejunal interposition. To the best of our knowledge, this is 


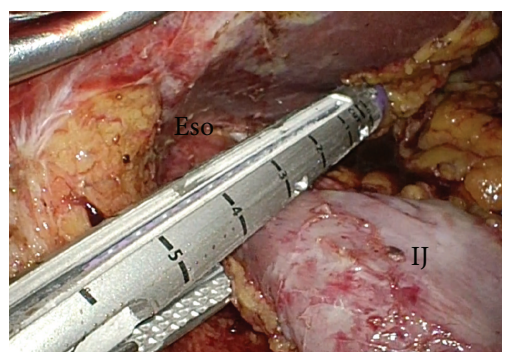

(a)

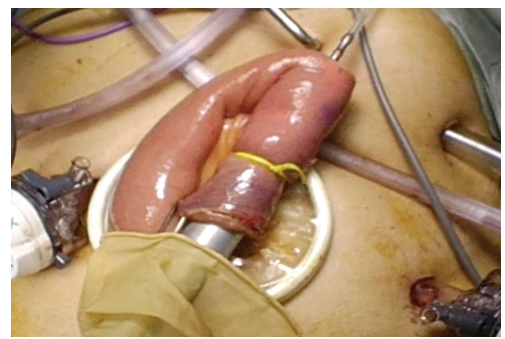

(c)

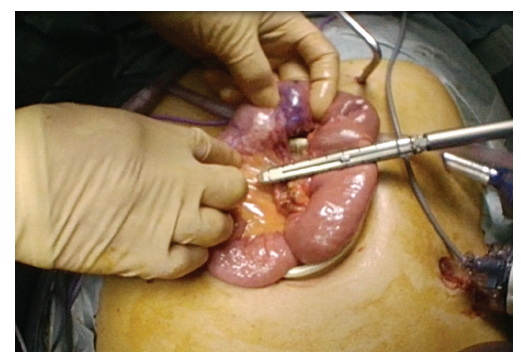

(b)

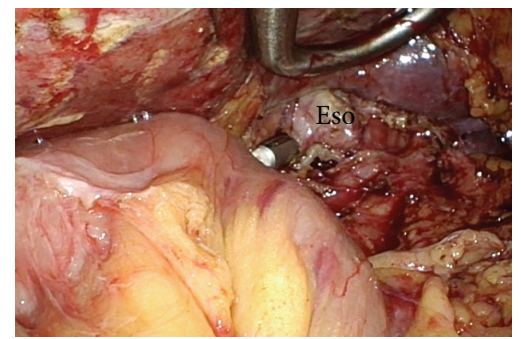

(d)

FIGURE 2: Reconstruction at laparoscopic remnant total gastrectomy. (a) The esophagus was transected using a linear stapler (GIA TriStaple $60 \mathrm{~mm}$, purple $60 \mathrm{~mm}$, Covidien) on the proximal side of the anastomosis of the esophagojejunostomy at initial proximal gastrectomy. (b) Jejunojejunostomy was carried out by side-to-side anastomosis using a linear stapler extracorporeally. (c, d) Esophagojejunostomy was performed by an end-to-side anastomosis using a circular stapler (DST Series EEA Staplers, $25 \mathrm{~mm}$, Covidien) intracorporeally (IJ; interposes jejunum, Eso; esophagus).

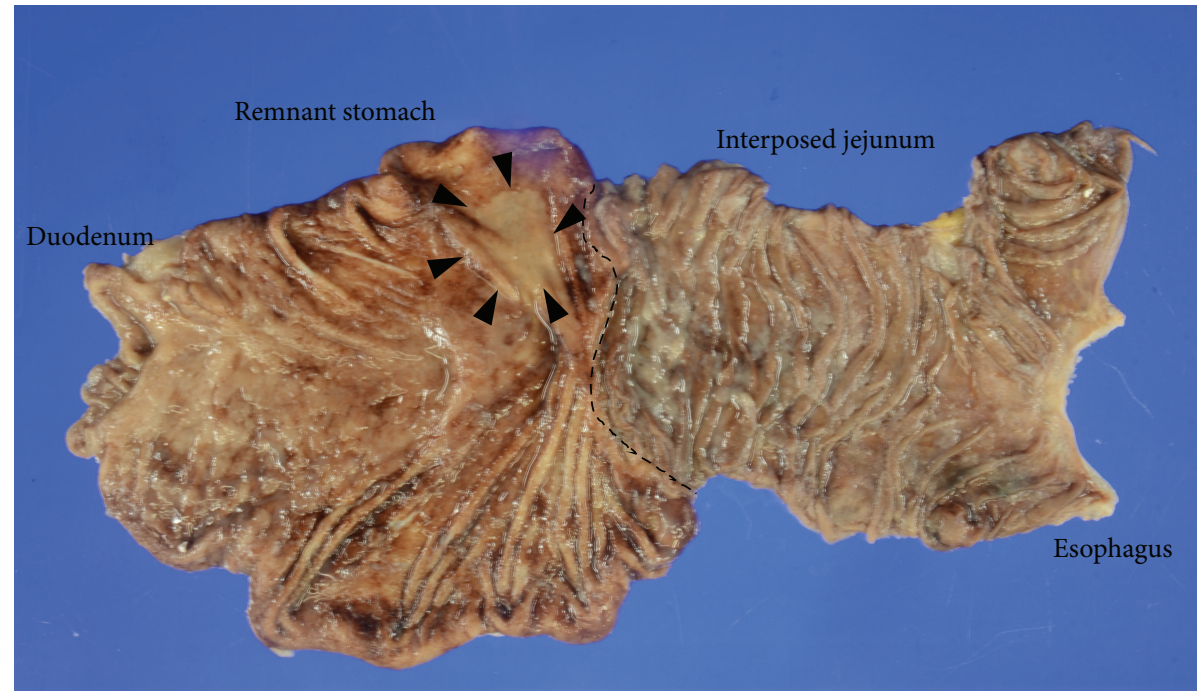

FIGURE 3: Resected specimen. The resected stomach contained a superficial depressed-type tumor, $37 \times 17 \mathrm{~mm}$ in size (black arrowhead). The black dote line showed the jejunogastrostomy at initial gastrectomy.

the first reported case of laparoscopic resection for remnant stomach reconstructed by jejunal interposition in the English language literature. In our case, the remnant total gastrectomy with en bloc lymphadenectomy could be completed easily and safely using a laparoscopic approach.

Remnant gastric cancer was originally defined as gastric cancer arising after distal gastrectomy for benign disease. More recently, remnant gastric cancer has been used to refer to all cancers arising in the remnant stomach, regardless of initial disease or operation. According to previous reports, with proximal gastrectomy becoming a conventional type of gastrectomy, the incidence of remnant cancer following proximal gastrectomy is increasing [15]. Ohyama et al. reported that gastric stump carcinoma following proximal gastrectomy occurred at a high frequency of $5.4 \%$ of initial resections and the time interval between the initial gastrectomy and the treatment of gastric stump cancer was within 5 years in 3 patients, within 5-10 years in 8 , and after 10 years in 6 . In our 
case, the occurrence of gastric remnant cancer was 7 years after the initial surgery.

Yamada et al. [4] first reported a laparoscopy-assisted complete gastrectomy for patients with early gastric remnant cancer in 2005. Since then, there have been increasing reports of successful laparoscopy-assisted gastrectomy for gastric remnant cancer. To date, just a hundred patients have undergone it by a laparoscopic approach for remnant gastric cancer [12]. Among these, laparoscopic total gastrectomy following proximal gastrectomy was reported in only three cases $[8,9$, 12]. Proximal gastrectomy is performed widely as a functionpreserving operation for early gastric cancer located in the upper third of the stomach. In terms of reconstruction after proximal gastrectomy, three reconstruction methods are mainly used: esophagogastrostomy [16, 17], jejunal interposition [18-20], and double-tract method [21]. To avoid reflux esophagitis after proximal gastrectomy, jejunal interposition has been selected for the reconstruction method in our department since 1973 and, to date, more than 200 cases have undergone this surgical procedure [22]. All of the three reported cases $[8,9,12]$ were initial reconstruction of esophagogastrostomy; this is the first reported case of laparoscopic resection for remnant stomach reconstructed by jejunal interposition in the English language literature.

Cases of resection for remnant stomach reconstructed by jejunal interposition have been rarely reported, even in open surgery. Nozaki et al. reported five cases with removal of remnant gastric cancer following proximal gastrectomy with jejunal interposition [23]. The unique technique of Nozaki et al. was preserving the interposed jejunum for re-reconstruction by Roux-en-Y anastomosis. In our case, removal of the total gastric remnant with radical lymphadenectomy was the same as that of Nozaki et al. On the other hand, the interposed jejunum was totally removed at the same time. In our case, the first reason for the total removal of interposed jejunum was the difficulty of safely preserving the vessels feeding the interposed jejunum owing to severe adhesions. The second reason for the total removal of interposed jejunum was that esophagojejunostomy was a usual and safe anastomotic technique after laparoscopy-assisted total gastrectomy or proximal gastrectomy. Accordingly, we selected total removal of the gastric remnant with interposed jejunum and rereconstruction by the Roux-en-Y method.

The selected surgical approach after major surgery for intra-abdominal malignancies has usually been the conventional open method. Kwon et al. [10] and Son et al. [9] reported a comparison of the surgical outcomes between an open approach group and a minimally invasive approach group for patients with remnant gastric cancer. In their report, compared with the open approach group, the minimally invasive approach group for remnant gastric cancer demonstrated better short-term outcome and comparable oncologic results. On the other hand, eight of 17 patients (47.1\%) required conversion to open surgery because of the presence of severe intra-abdominal adhesions [9]. Adhesion formation is one of the major concerns in patients who undergo major abdominal surgery. In laparoscopic surgery after major abdominal surgery, the first key to a safe procedure is the insertion of the first trocar in an area free from adhesion. In our case, the first trocar was inserted from the left lower oblique to an open method. The second key was careful lysis of adhesion from the abdominal wall. If all trocars are inserted at the same site of laparoscopic gastrectomy, removal of remnant stomach, and lymphadenectomy, reconstruction might be performed by the usual method easily.

\section{Conclusion}

We have described a good result of a laparoscopic approach for early gastric remnant cancer following radical proximal gastrectomy. A review of the literature supports a minimally invasive approach for this procedure, showing that it is safe, effective, and technically feasible.

\section{Consent}

Written informed consent was obtained from the patient for publication of this case report and any accompanying images.

\section{Conflict of Interests}

Kazuhito Yajima and the other coauthors have no conflict of interests.

\section{References}

[1] I. Uyama, A. Sugioka, J. Fujita et al., "Completely laparoscopic extraperigastric lymph node dissection for gastric malignancies located in the middle or lower third of the stomach," Gastric Cancer, vol. 2, pp. 186-190, 1999.

[2] S. Kitano, N. Shiraishi, I. Uyama, K. Sugihara, and N. Tanigawa, "A multicenter study on oncologic outcome of laparoscopic gastrectomy for early cancer in Japan," Annals of Surgery, vol. 245, no. 1, pp. 68-72, 2007.

[3] H. Katai, M. Sasako, H. Fukuda et al., "Safety and feasibility of laparoscopy-assisted distal gastrectomy with suprapancreatic nodal dissection for clinical stage I gastric cancer: a multicenter phase II trial (JCOG 0703)," Gastric Cancer, vol. 13, no. 4, pp. 238-244, 2010.

[4] H. Yamada, K. Kojima, T. Yamashita, T. Kawano, K. Sugihara, and Z. Nihei, "Laparoscopy-assisted resection of gastric remnant cancer," Surgical Laparoscopy, Endoscopy and Percutaneous Techniques, vol. 15, no. 4, pp. 226-229, 2005.

[5] F. Corcione, F. Pirozzi, E. Marzano, D. Cuccurullo, A. Settembre, and L. Miranda, "Laparoscopic approach to gastric remnantstump: our initial successful experience on 3 cases," Surgical Laparoscopy, Endoscopy and Percutaneous Techniques, vol. 18, no. 5, pp. 502-505, 2008.

[6] H. J. Cho, W. Kim, H. Hur, and H. M. Jeon, "Laparoscopyassisted completion total gastrectomy for gastric cancer in remnant stomach: report of 2 cases," Surgical Laparoscopy, Endoscopy and Percutaneous Techniques, vol. 19, no. 2, pp. e57-e60, 2009.

[7] T. Shinohara, N. Hanyu, Y. Tanaka, K. Murakami, A. Watanabe, and K. Yanaga, "Totally laparoscopic complete resection of the remnant stomach for gastric cancer," Langenbeck's Archives of Surgery, vol. 398, no. 2, pp. 341-345, 2013.

[8] E. Nagai, K. Nakata, K. Ohuchida, Y. Miyasaka, S. Shimizu, and M. Tanaka, "Laparoscopic total gastrectomy for remnant 
gastric cancer: feasibility study," Surgical Endoscopy and Other Interventional Techniques, vol. 28, no. 1, pp. 289-296, 2014.

[9] S.-Y. Son, C. M. Lee, D.-H. Jung et al., "Laparoscopic completion total gastrectomy for remnant gastric cancer: a singleinstitution experience," Gastric Cancer, vol. 18, no. 1, pp. 177-182, 2015.

[10] I. G. Kwon, I. Cho, A. Guner et al., "Minimally invasive surgery for remnant gastric cancer: a comparison with open surgery," Surgical Endoscopy and Other Interventional Techniques, vol. 28, no. 8, pp. 2452-2458, 2014.

[11] H. S. Kim, B. S. Kim, I. S. Lee, S. Lee, and J. H. Yook, "Laparoscopic gastrectomy in patients with previous gastrectomy for gastric cancer: a report of 17 cases," Surgical Laparoscopy, Endoscopy, and Percutaneous Techniques, vol. 24, no. 2, pp. 177182, 2014.

[12] S. Tsunoda, H. Okabe, E. Tanaka et al., "Laparoscopic gastrectomy for remnant gastric cancer: a comprehensive review and case series," Gastric Cancer, vol. 19, no. 1, pp. 287-292, 2016.

[13] Japanese Gastric Cancer Association, "Japanese gastric cancer treatment guidelines 2010, ver. 3," Gastric Cancer, vol. 14, pp. 113-123, 2011.

[14] Japanese Gastric Cancer Association, "Japanese classification of gastric carcinoma. 3rd English edition," Gastric Cancer, vol. 14, no. 2, pp. 101-112, 2011.

[15] S. Ohyama, M. Tokunaga, N. Hiki et al., "A clinicopathological study of gastric stump carcinoma following proximal gastrectomy," Gastric Cancer, vol. 12, no. 2, pp. 88-94, 2009.

[16] S. Sakuramoto, K. Yamashita, S. Kikuchi et al., "Clinical experience of laparoscopy-assisted proximal gastrectomy with Toupet-like partial fundoplication in early gastric cancer for preventing reflux esophagitis," Journal of the American College of Surgeons, vol. 209, no. 3, pp. 344-351, 2009.

[17] Y. Adachi, T. Katsuta, M. Aramaki, A. Morimoto, N. Shiraishi, and S. Kitano, "Proximal gastrectomy and gastric tube reconstruction for early cancer of the gastric cardia," Digestive Surgery, vol. 16, no. 6, pp. 468-470, 1999.

[18] I. Uyama, A. Sugioka, J. Fujita, Y. Komori, H. Matsui, and A. Hasumi, "Completely laparoscopic proximal gastrectomy with jejunal interposition and lymphadenectomy," Journal of the American College of Surgeons, vol. 191, no. 1, pp. 114-119, 2000.

[19] H. Katai, T. Sano, T. Fukagawa, H. Shinohara, and M. Sasako, "Prospective study of proximal gastrectomy for early gastric cancer in the upper third of the stomach," British Journal of Surgery, vol. 90, no. 7, pp. 850-853, 2003.

[20] T. Kinoshita, N. Gotohda, Y. Kato, S. Takahashi, M. Konishi, and T. Kinoshita, "Laparoscopic proximal gastrectomy with jejunal interposition for gastric cancer in the proximal third of the stomach: a retrospective comparison with open surgery," Surgical Endoscopy and Other Interventional Techniques, vol. 27, no. 1, pp. 146-153, 2013.

[21] S.-H. Ahn, D. H. Jung, S.-Y. Son, C.-M. Lee, D. J. Park, and H.H. Kim, "Laparoscopic double-tract proximal gastrectomy for proximal early gastric cancer," Gastric Cancer, vol. 17, no. 3, pp. 562-570, 2014.

[22] T. Suzuki, Y. Awane, M. Kitamura, T. Konishi, K. Arai, and G. Kosaki, "Indication of proximal gastrectomy for gastric cancer," Japanese Society of Gastroenterological Surgery, vol. 19, no. 1, pp. 1-11, 1986 (Japanese).

[23] I. Nozaki, S. Hato, and A. Kurita, "A new technique for resecting gastric remnant cancer after proximal gastrectomy with jejunal interposition," Surgery Today, vol. 42, no. 11, pp. 1135-1138, 2012. 


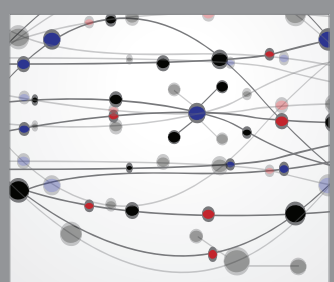

The Scientific World Journal
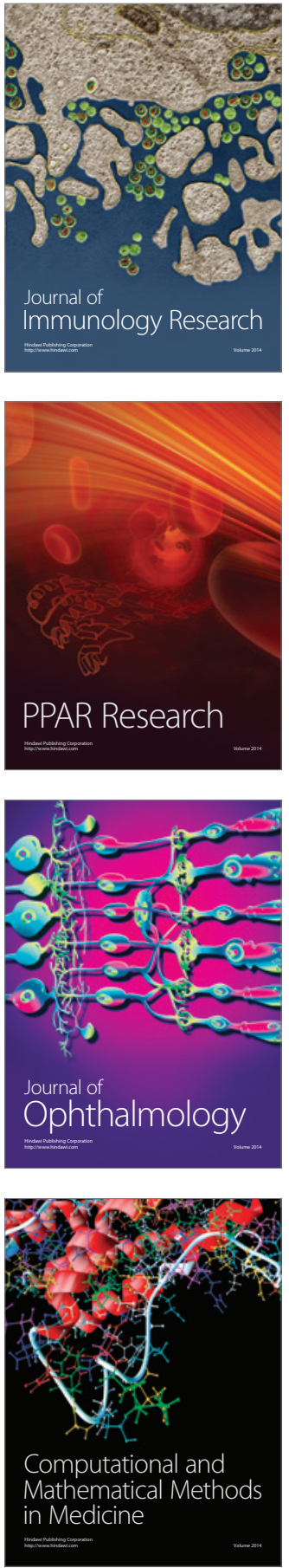

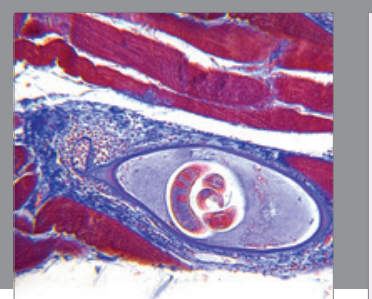

Gastroenterology Research and Practice

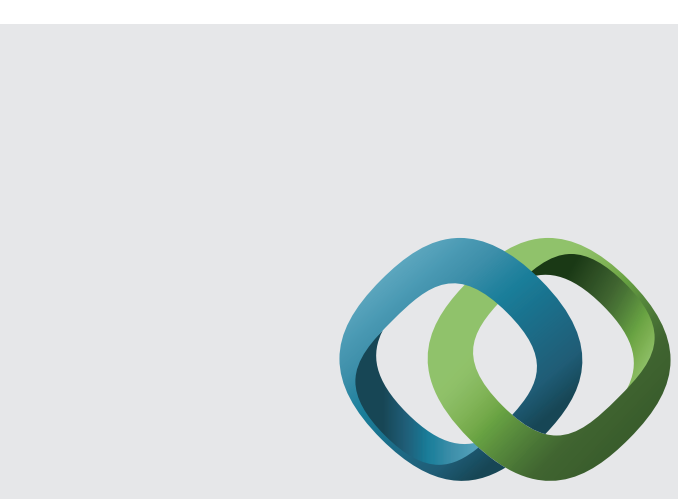

\section{Hindawi}

Submit your manuscripts at

http://www.hindawi.com
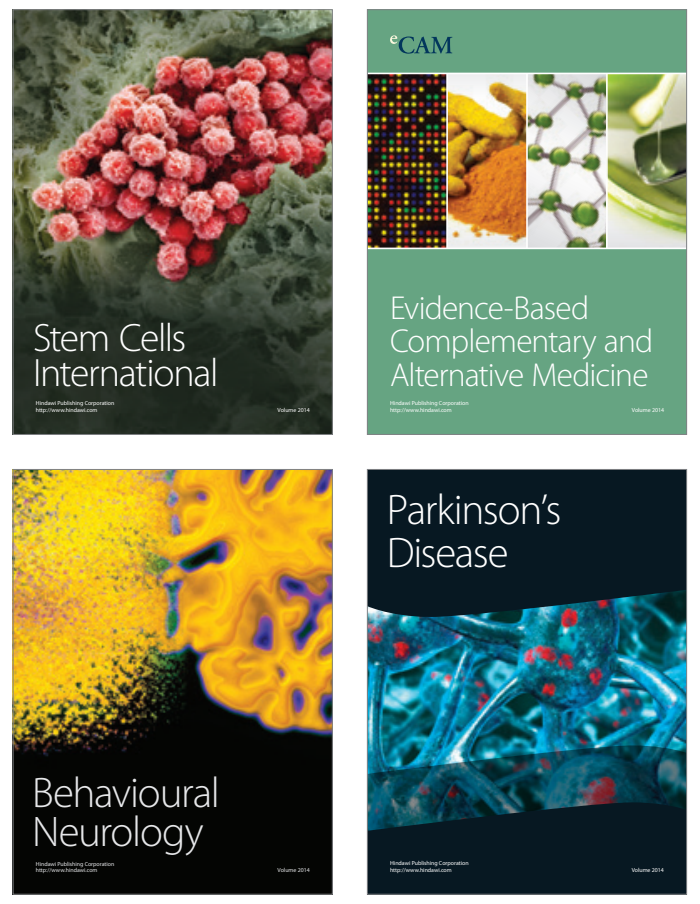
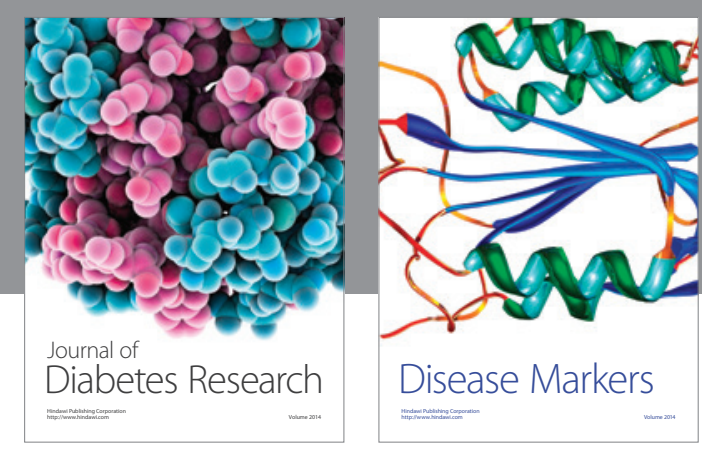

Disease Markers
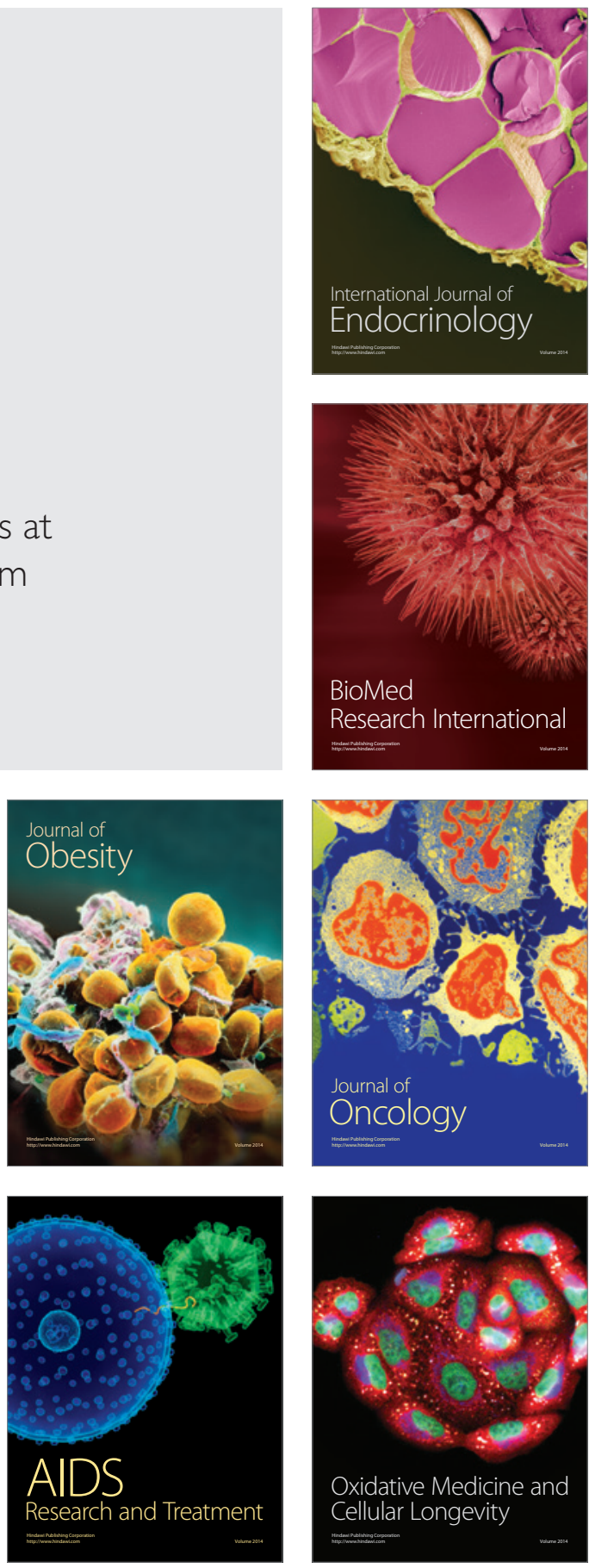